\title{
Transition inertia due to competition in supply chains with remanufacturing and recycling: A systems dynamics model
}

\begin{abstract}
This paper studies the link between capital goods supply chains and sociotechnical transitions. Research on the latter has so far tended to focus on sustainability, energy and transport systems. Despite the considerable shift from products to services, supply chains are an integral element of most sociotechnical systems and there seems to be no foreseeable substitute for them. Consequently, for transitions to sustainability to take place, the inertia of supply chains in these systems has to be overcome and their environmental impact reduced. The paper explores this with a system dynamics model of a supply chain. While remanufacturing of used products by the retailer and recycling by the supplier can reduce the environmental impact of the supply chain, competition in the market between new and remanufactured products forces them into a situation where improving business and environmental performance is difficult.
\end{abstract}

Keywords: transitions, inertia, supply chain, remanufacturing, recycling

\section{Highlights}

- Supply chains are an indispensible part of many sociotechnical systems despite the shift from products to services.

- The paper considers the link between supply chain and sociotechnical transition research.

- Competitive responses based on exploiting current firm advantages can keep supply chain strategies locked in.

- For sustainability transitions, competition barriers at the supply chain level must be overcome.

- Transition through the growth of emergent niches of sustainable supply chains is difficult.

\section{Introduction}

There is a considerable amount of research on sociotechnical system transitions with an emphasis on transitions to sustainability (Geels, 2011). A particular focus has been placed on energy and transport systems that cater for a considerable number of everyday human needs. Despite the shift from products to services of modern industrial systems (Oliva and Kallenberg, 2003; Kastalli and Van Looy, 2013) supply chains are needed to satisfy individual consumer and business needs through capital and consumer goods. Inevitably supply chains being part of 
a sociotechnical system, they also contribute to its inertia. Therefore a transition towards sustainability requires that the operation of supply chains (micro level) be altered as well towards modes of operation with lower carbon emissions, material disposal and environmental impact. These alternative operational modes are referred to in the literature as "green" supply chain or closed loop supply chains (Guide and Van Wassenhove, 2009; Sarkis et al., 2011). The importance of supply chains as integral elements of sociotechnical systems implies that the relevance of their operations and operations strategies for transition processes must be explored.

The present article provides a first step in this direction. It explores a supply chain where in the forward channel Original Equipment Manufacturers (OEM) cooperate with retailers in selling brand new products and compete with them in the reverse channel when the latter start remanufacturing used industrial products and reselling them (e.g. electric motors, tires, appliances). Remanufacturing entails bringing used products back into an "as good as new" condition through the processes of disassembly, overhaul and replacement operations (Fleischmann et al., 1997). The supply chain is assumed to operate in a sociotechnical regime, as an intermediary between its technical and social system elements that supply a societal need. Operating in a competitive, profit making, business environment, the OEM has to respond in a competitive way to maintain its brand (new) product market segment against an expanding segment for remanufactured products. In both segments customers seek product functionality, which is an increasingly relevant consideration in a transition to a circular economy context (Ellen McArthur Foundation, 2012).

Investigating how a single OEM and a retailer compete in supplying the market with new and remanufactured products, is analogous to analysing how a small niche with potentially reduced environmental impact can form in isolation from the rest of the regime. A system dynamics model (Sterman, 2000) is developed where competition in the supply chain is conceptualised using the Resource Based View (Barney, 1986). A range of OEM strategic responses to competition from remanufactured products is analysed, such as acting preemptively and recycling used products or improving its production processes. It is assumed that facing the well-known "exploration vs exploitation dilemma" (March, 1991), the OEM commits to strategies that allow him to exploit his current resources rather than develop and explore the possibilities offered by new ones. The model is used to answer the following questions:

1. What is the effect of response strategies for the OEM? 
2. Are the OEM's response strategies consistent with improving the environmental performance of the supply chain?

Simulation results show that in a competitive, profit making business regime, responses that improve the environmental impact of the supply chain cannot improve the competitive position of the OEM vis a vis competition from remanufactured products. The analysis excludes competition from other supply chains. The paper discusses why it is not likely that supply chain actors will manage their operations towards a more sustainable closed loop configuration. The implication is that supply chain actors will remain locked-in in a mode of interaction that blocks the sociotechnical system from moving in a sustainability direction and hence contributes to system inertia. The supply chain will continue to operate primarily in a forward mode, supplying brand new products to the market.

The remainder of this article is organised as follows: Section 2 provides a background discussion on supply chains, section 3 discusses competition in reverse supply chains, and section 4 presents a qualitative model of the exemplary case in the paper. Next, in section 5 a system dynamics model is developed while model results are presented and discussed in section 6. Section 7 discusses why supply chain actors in a competitive business regime will likely remain in a lock-in situation rather than radically alter their trajectory. Section 8 concludes.

\section{Firms in closed supply chains: An overview}

In response to the increased internal sociotechnical pressures, such as stricter regulations and increased customer demand, companies need to develop their capabilities in assessing, managing and controlling the environmental performance of their operations (Bjorklund et al., 2012). This has manifested itself along different directions with varying degrees of commitment and mixed results in actually contributing to environmental protection (Jermier and Forbes, 2003). Recycling and remanufacturing of used products have been strategies in this direction, frequently driven by national and international environmental legislation (TibbenLembke, 2002). Given the nature of profit-seeking organisations, these strategies provide favorable outcomes when they are aligned with corporate (Hart, 1995; Porter and Reinhardt, 2007) and operations strategies (Burgos Jiménez and Céspedes Lorente, 2001; Heese et al., 2005; Kleindorfer et al., 2005; Newman and Hanna, 1996; Sarkis, 1995; Sundin and Bras, 
2005). Whether this is achievable or not, has been the subject of extensive debate (Jones and Levy, 2007).

Engagement in recycling or remanufacturing operations introduces new forms of competition between Original Equipment Manufacturers (OEM) brand new and remanufactured products and between OEMs and local remanufacturers (Matsumoto, 2009). Consequently, sometimes OEMs may engage in remanufacturing or recycling as a reaction to the presence of competing OEMs or third party remanufacturers, including their own resellers and retailers, rather than a proactive environmental strategic move (Seitz, 2007; Matsumoto and Umeda, 2011). Overall, facing competition from remanufactured products an OEM response can take six forms (Atasu et al., 2008; Atasu at al., 2009; Toffel, 2004): (i) do nothing, i.e. ignore the competition from other OEM or local remanufacturers (ii) remanufacture and compete on prices with other OEM that offer remanufactured products, or other products that can be considered as substitutes for remanufactured ones, (iii) co-operate with third party remanufacturers to ensure that they uphold the quality standards of its products and services, (iv) pre-empt the entry of third party remanufacturers by using contractual means, such as leasing, provision of payback incentives and possibly launch a remanufacturing operation, (v) launch a collection operation so that used products never reach third party remanufacturers (and possibly launch a remanufacturing operation), or (vi) compete directly with local remanufacturers at the operations level to make new products more attractive than remanufactured ones for customers and collect used products for recycling.

All of the above alternatives, apart from (i) and (vi), have been studied. They focus on business performance, while environmental issues received less attention. Compared to the vast literature on closed loop supply chains (Guide and Van Wassenhove, 2009), very little attention has been paid to competition in remanufacturing supply chains (Mitra and Webster, 2008; Östlin et al., 2008; Toffel, 2004; Kleber et al., 2011; Ferguson and Toktay, 2006; Debo et al., 2006; Qiang et al., 2013). The model developed in this article explores alternative (vi) and tries to explore both competition and environmental performance.

OEMs and retailers cooperate to increase the value offered in brand new products, while at the same time retailers recover part of the value embedded in used products through remanufacturing and compete by offering them in the market. The OEMs may refrain from remanufacturing products for a number of reasons. It may cannibalise their brand product sales 
(Atasu et al., 2009) or the remanufacturing costs may be excessive due to, for example, high transportation costs (Seitz, 2007). In other cases, the retailers may simply take advantage of their market proximity and close seller-customer relationships (Östlin et al., 2008). When customers value mostly product functionality, for example, when their choices are not influenced by brand name or aesthetics, OEM products face direct competition from the remanufactured products of the retailer. Since both kinds of products have comparatively similar characteristics, in addition to the importance of having full or equivalent functionality, competition in this case concerns also prices and dependability (on-time delivery) (Hazen et al., 2012).

Two issues from the literature on supply chains operations strategy are addressed in the model presented in the following sections: first, the case of a non-remanufacturing OEM competing with its remanufacturing retailers, which has not yet been explored; second, the effects of competition on the natural environment, which has hardly received attention (Papachristos and Adamides, 2013). This is an issue that is relevant to sociotechnical transitions to sustainability research.

\section{Analyzing competition in supply chains}

In order to frame and analyse the competition between the OEM and retailer-remanufacturer, the Resource-Based View (RBV) of competition is utilised. In this strategic management framework, firms are viewed as entities possessing heterogeneous, complex ensembles of resources (Barney et al., 2001). The use of resources that are scarce or unique, immobile, inimitable and unsubstitutable, durable, and complementary are thought to contribute to the firm's competitive advantage. The RBV is used to explain how superior firm performance and competitive advantage emerges from these unique configurations of resources, capabilities and mechanisms to differentiate them from competition (Morecroft, 2002; Rumelt, 1984; Teece, 1984; Wernerfelt, 1984; Teece et al., 1997). A thorough understanding of a firm's resources can then be translated into specific and concrete operations strategy decisions that guide the accumulation of firm capabilities (Slack and Lewis, 2002).

Since, the competition case in this paper concerns products with similar characteristics, there is limited room for strategic response through the development of unique firm resources. The OEM and the retailers have similar resources at their disposal in order to achieve the same operations strategy performance objectives. Consequently, the strategic response of the OEMs 
to competition from retailers - turned remanufacturers, must aim at managing the dynamics of these similar resources, so that OEM resource stock levels remain higher or improve faster than the corresponding stock levels of the retailer (Dierickx and Cool, 1989; Kunc and Morecroft, 2009).

Speed and flexibility are not important operations strategy performance objectives for the case of supply chain competition in the sector of capital goods, while quality is linked to the resource stock of production know-how which increases with cumulative production. Since quality is not a direct order winning criterion (Hill, 2000), the net effect of the improvement of the production operations is reflected in the reduced product unit cost. OEM resources include manufacturing capacity and product technology. Their stock levels determine the OEM product market share, which is assumed to correspond to the level of the customer demand resource stock. OEM competitiveness also depends on product unit cost/price and availability which are influenced by the use of recycled raw materials (hence recycling technology resources) and production capacity. Both of them develop gradually in accordance with the development of capacity and production know-how. The operations strategy related resources of the remanufacturer are remanufacturing capacity, customer trust (trust is a matter of geographic proximity and frequent face-to-face interaction), and number of customers. The last two resources have a mutually reinforcing relationship, so that the measurement of customers is a sufficient indicator of the state of both resources.

Competition under the Resource Based View concerns the management of these resources and their accumulation processes by OEMs and remanufacturers (Dierickx and Cool, 1989). Preventing a competitor to achieve the same, or higher levels of resource stocks is possible by either accelerating the inflow of one's own resources, or slowing down those of the competitor/imitator or both. This is possible because in the case considered, firm resources are directly linked to the flow of products in the forward and reverse channels of the supply chain. There are certain characteristics of resource accumulation processes that must be considered in forming OEM strategic responses (Dierickx and Cool, 1989). First, it is difficult to achieve the same level of stock in much less time (time compression diseconomies) therefore a preemptive resource development operation strategy must be adopted in order to maintain higher stock levels even when competitors have faster resource accumulation processes. The same pre-emptive strategy seems appropriate when a competitor aims at taking advantage of asset mass efficiencies (high stock levels reinforce the related rates of increase). Second, the 
characteristic of the interconnectedness of resource stocks implies that strategies for regulating resource flows at different points in the network of stocks and flows, may have indirect impact on the associated stocks.

In this context, the management of tangible and intangible firm resource stocks associated with firm performance objectives can be accomplished at the operations level by regulating the associated resource flows through four broad operations strategy decision areas (Slack and Lewis, 2002): (i) capacity management decisions that concern the production and recycling rate of OEMs and the rate of remanufacturing by the retailers, (ii) supply chain and logistics management decisions which concern the flow of new and used products in the supply chain, and the way capacity is being used, (iii) organisational learning and operational improvement decisions which concern the accumulation rate of the production know-how resource stock for manufacturing, remanufacturing, and recycling operations, and (iv) decisions on the rate of acquisition and use of product and process technology. In the case considered in the paper, it is assumed that both competitors have equal access to product and process technology factor markets, and that products are not technologically complex, so that technology acquisition cannot be considered as a distinct strategic decision area which contributes to any operations strategic objective.

Generally, production improvements that rely on learning-by-doing tend to increase the production efficiency and reduce costs with cumulative production. Usually, competitors cannot take advantage of the time compression diseconomies associated with them. However, in the case explored in this paper, the OEM cannot rely on time compression diseconomies based on their manufacturing experience relative to retailers. The latter can easily reach the same effective level of production efficiency or cost as they have a relatively simpler remanufacturing task. Hence, remanufacturers will be in a superior position, in terms of cost and dependability and it will be the OEMs that will have to improve their efficiency.

Anticipating this situation, the OEM responses can be: (i) manage strategically their capacity and production know-how by pre-emptively developing recycling capacity, (ii) accelerate their production related learning, so that more used products are attracted, and recycling contributes more to the cost reduction of brand products (asset mass efficiency), or (iii) take advantage of the dependence that the retailers have on them, and intentionally fulfil partially their orders (rationing), in order to regulate the flow of new products to the market in a manner that creates 
an undersupply or delayed oversupply of used products to the retailer's remanufacturing operations. Thus, it is anticipated that retailers will be either: (i) short of capacity, have backlogs and are obliged to reduce their collection effort and forward the products collected for recycling to the OEMs, or (ii) they will suffer from capacity underutilisation and high costs. Either case is expected to lead to reduced retailer competitiveness. However, it is not clear whether increased OEM competitiveness can simultaneously reduce the environmental impact as well. Evaluating the business and environmental performance of these strategies that relate to dynamic supply chain management processes is a complex task due to feedback and delay interdependences between the firm resource accumulation flows (Morecroft, 2002). To overcome these difficulties, the use of system dynamic models of resource-based competition has been proposed (Großler, 2007; Mollona, 2002; Morecroft, 2002). A model of this type is developed in the following sections and is used to explore trade-offs and synergies in business and environmental strategic objectives.

\section{Modelling assumptions}

The model concerns a single product, with two market segments to which a retailer sells OEM brand new products and its own remanufactured products. The retailer is assumed to serve a geographically-bounded market where there is no competition from other OEMs. It is the sole collector of used products which are remanufactured subject to capacity constraints. Excess inventory of used products are shipped back to the OEM for recycling where recycled materials are used in the production of new products. There are two reasons for assuming a geographic constraint. First it simplifies the competitive setting. Second, it makes sense from a sociotechnical perspective. Sociotechnical transitions come about when developments in niches, regimes and landscape coalesce and the interactions between them, subject to their nature and timing being right, bring about a change (Geels and Schot, 2007). Looking at how a single OEM and a retailer interact in supplying a market competitively, is analogous to analysing how a small niche can form in isolation from the rest of the regime.

Following a sociotechnical perspective (Grin et al., 2010), the model allows for a bidirectional flow of customers between brand (new) and remanufactured product market segments according to the relative attractiveness of each competitor's products. Attractiveness is a model variable defined for each competitor as an aggregate measure that combines brand strength, product price and availability. Brand strength for new or remanufactured products is related to the company's existing customer base and price is a function of production cost. It is assumed 
that initially the remanufactured product market is only a small fraction of the total market and that the sociotechnical regime is stable.

It is assumed that the retailer supplies equally the demand for new and remanufactured products. Anticipating demand levels the retailer initiates the development of remanufacturing capacity with a certain level of expectation and commitment, and improves its operations with time becoming more efficient in collecting and processing used products. The OEM manages its recycling capacity in a similar way, though it can use its resources to develop its recycling capacity faster than that of the remanufacturer. The retailer supplies the market with remanufactured products that have a lower selling price than new ones. In both cases, product pricing is dynamic and depends on unit production costs and learning effects in manufacturing, remanufacturing and recycling processes. In addition, OEM production cost is proportional to the amount of products that are recycled to provide raw material for the production of new ones.

A qualitative representation of the model based on the previous discussion of assumptions made is shown in Figure 1. Arrows represent the process and information structure of the system and show how they determine its behaviour (Sterman, 2000). The dynamics of individual loops are contingent on the relationships (positive + , negative - , and delayed $=$ ) between the elements/variables. At the top of Figure 1 there are two competing re-inforcing loops around the resources Sales of Brand Products and Sales of Remanufactured Products. The levels of both resources have a reinforcing effect on Demand for Brand Products and Demand for Remanufactured Products, through increased Brand Attractiveness (new) and Brand Attractiveness (remanufactured), respectively. The relative values of demand determine the attractiveness of each product type. Demand depends on the existing customer base, on product availability (Backlog of Brand Products and Backlog of Remanufactured Products) and the prices/costs of products which directly depend on their cost of production (Cost/Price of Brand Products and Cost/Price of Remanufactured). In both cases, the unit cost of products is subject to learning effects. Since, the rate of OEM production follows the demand rate, the greater the Demand for Brand Products, the greater the Learning Effect, the lower the Cost/Price of Brand Products, and closing the loop again, the greater the Demand for Brand Products. 


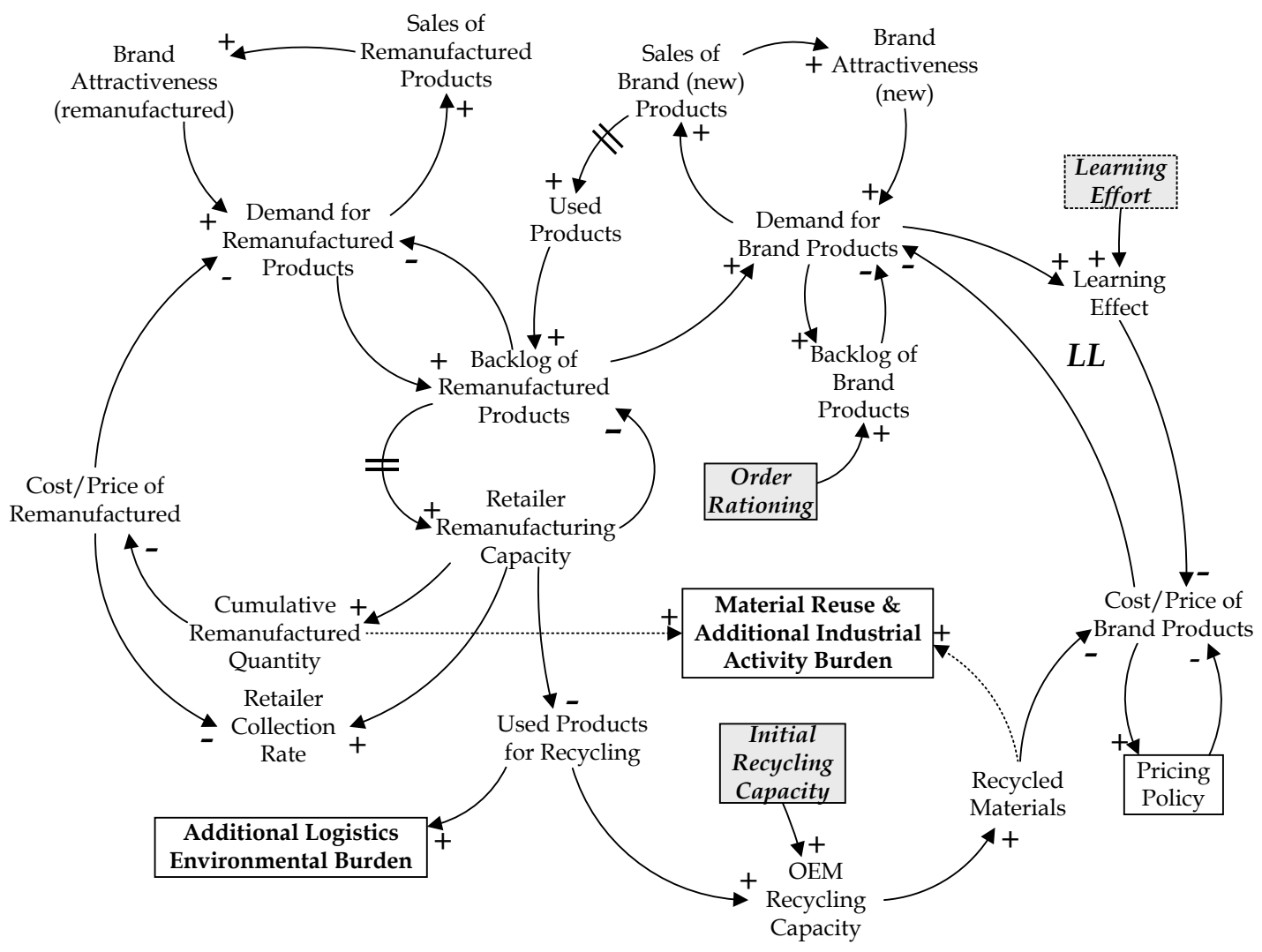

Figure 1 A qualitative system dynamics representation of competition in the remanufacturing supply chain.

The quantitative model developed in the next section, includes exogenous decision variables (shown in grey) which correspond to the OEM operations strategy decisions discussed in section 3. For example, increased values of Learning Effort result in lower product unit cost/price. The use of additional Recycled Materials in production instead of raw materials may have a similar effect. Recycling activity is possible when OEM Recycling Capacity and volume of used products are available. Therefore, the OEM attracts more used products for recycling when it has available recycling capacity (Initial Recycling Capacity) and before the remanufacturer starts building up its capacity. Finally, by rationing the retailer/remanufacturer orders (Order Rationing) and by taking advantage of the delays in the system, the OEM may cause undercapacity or overcapacity of the retailer's remanufacturing operations.

The environmental impact that these strategies have, depends on the amount of recycled and remanufactured products, the additional industrial activity introduced into the system (energy consumption and pollution), and the additional transportation logistics involved in recycling and remanufacturing (again, energy consumption and pollution). The system dynamics simulation model in the following section implements the qualitative representation as a network of interconnected resource stocks and flows. 


\section{Detailed description of the system dynamics model}

The core material flows and decision structure of the system dynamics model is depicted in Figure 2 (OEM strategic response variables are shown in grey). Resources are modelled as stocks whereas resource accumulation and depletion activities and processes are represented as flows (Morecroft, 2007). Usually, the rates of activity are regulated by auxiliary variables, as well as by the levels of resource stocks. In the model, the forward supply channel starts with OEM_Materials_Procurement and ends with Sales_of_Brand_Products. The reverse channel starts from Inventory_in_Use which is collected and either remanufactured and sold (Sales_of_Remanufactured_Products) or, recycled and fed back into production (OEM_Recycling).

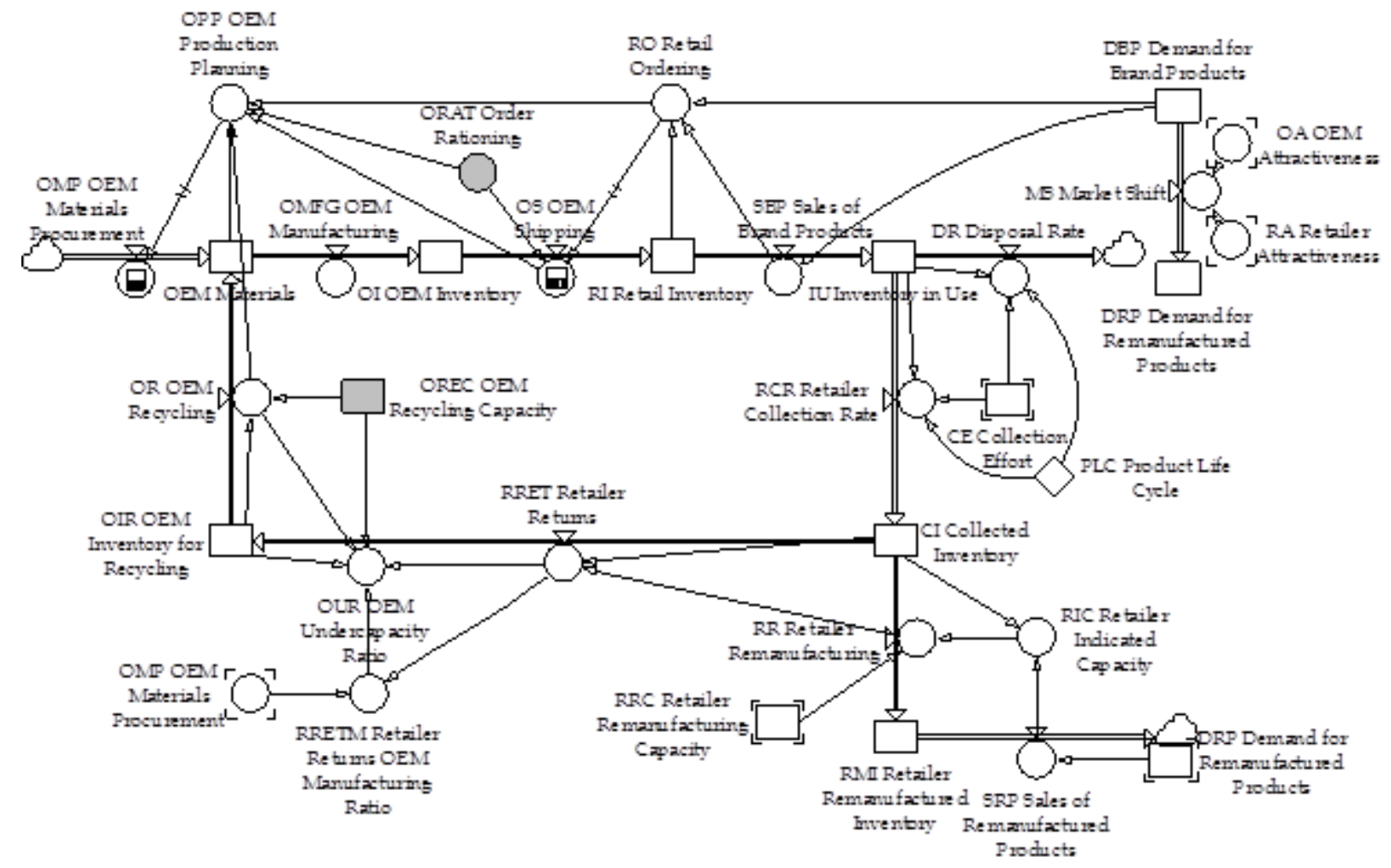

Figure 2 Core stock and flow structure of the supply chain model.

The retail price of remanufactured and brand products (Figure 3) is modelled using similar structures as shown below where the OEM_Learning_Exponent corresponds to Learning_Effort of Figure 1: 


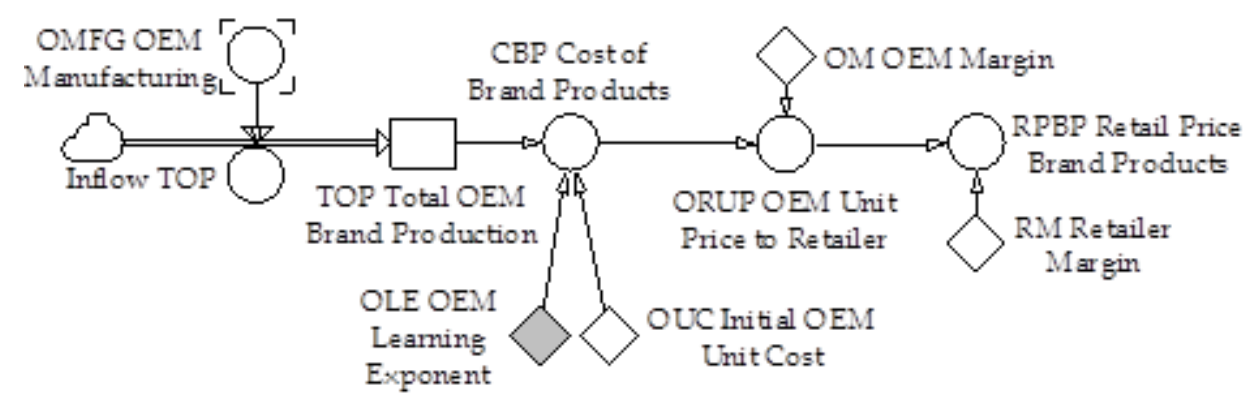

Figure 3 Model structure for brand product retail prices.

Total OEM brand production is: $\quad \mathrm{TOP}(\mathrm{t})=\int_{0}^{\mathrm{t}}[\operatorname{InflowTOP}(\mathrm{t})] \mathrm{dt}$

Production cost of brand products is: $\mathrm{CBP}(\mathrm{t})=\mathrm{OUC}+\mathrm{TOP}(\mathrm{t})^{\mathrm{OLE}}$

Retail price of brand products is: $\quad \operatorname{RPBP}(\mathrm{t})=\mathrm{ORUP}(\mathrm{t}) \times \mathrm{RM}$

The model structure used for calculating OEM and retailer attractiveness is shown below:

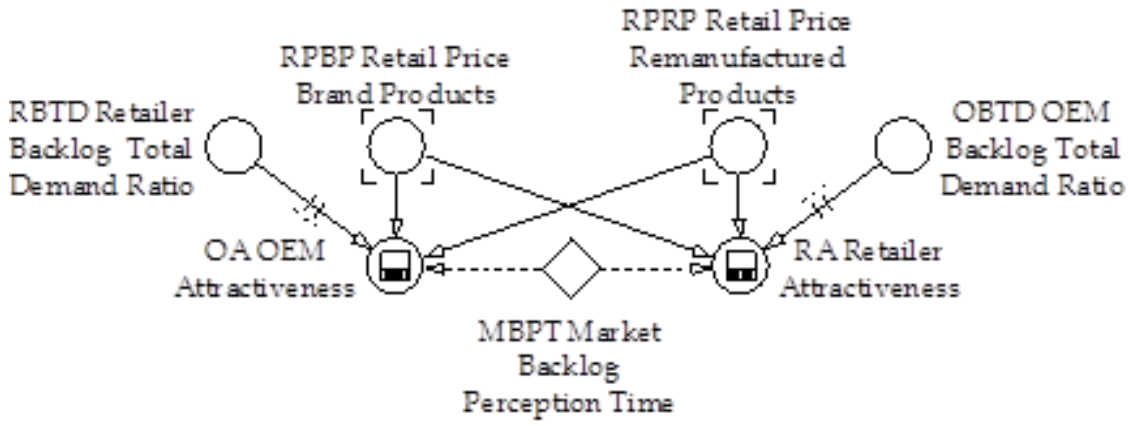

Figure 4 OEM and retailer attractiveness.

The flow of customers between the two market segments (Market_Shift) depends on the relative attractiveness of the product offerings of the two competitors (Retailer Attractiveness and OEM_Attractiveness) and the time it takes for consumer to perceive differentiation on them. The latter is linked to product order backlog and product retail prices. The equations for OEM and retailer attractiveness are:

$$
\begin{aligned}
& \operatorname{OA}(t)=\operatorname{MAX}\left(\operatorname{RPRP}(\mathrm{t}) / \operatorname{RPBP}(\mathrm{t}), \int_{-\mathrm{MBPT}}^{\mathrm{t}}[\operatorname{RBTD}(\mathrm{t})] \mathrm{dt} / \mathrm{MBPT}\right) \times \operatorname{RPRP}(\mathrm{t}) / \operatorname{RPBP}(\mathrm{t}) \\
& \operatorname{RA}(\mathrm{t})=\operatorname{MAX}\left(\operatorname{RPBP}(\mathrm{t}) / \operatorname{RPRP}(\mathrm{t}), \int_{-\mathrm{MBPT}}^{\mathrm{t}}[\operatorname{OBTD}(\mathrm{t})] \mathrm{dt} / \mathrm{MBPT}\right) \times \operatorname{RPBP}(\mathrm{t}) / \operatorname{RPRP}(\mathrm{t})
\end{aligned}
$$

Since the Market_Shift is a bidirectional flow between the two types of product demand, an increase in one triggers a proportional decrease in the other. Relationship (6) for MS(t) calculates the magnitude of the market shift (measured in products sold per year, one for each 
customer), while its direction is set by the relative attractiveness of the OEM's and retailer's products.

$$
\operatorname{MS}(\mathrm{t})=\operatorname{MAX}(\mathrm{RA}(\mathrm{t})-\mathrm{OA}(\mathrm{t}), \mathrm{OA}(\mathrm{t})-\mathrm{RA}(\mathrm{t})) /(O A(t)+R A(t))
$$

In the model, the retailer is assumed to collect all used products which are then stored temporarily, before and after remanufacturing, in $C I(t)$ and $R M I(t)$ stock variables respectively. If the retailer lacks remanufacturing capacity, collected products are forwarded to the OEM for recycling in $\operatorname{OIR}(t)$ stock which is given by:

$$
\operatorname{OIR}(\mathrm{t})=\int_{0}^{t}[\operatorname{RRET}(\mathrm{t})-\mathrm{OR}(\mathrm{t})] \mathrm{dt}(7)
$$

The retailer adds remanufacturing capacity according to his Retailer_Undercapacity. This takes into consideration the Retailer_Indicated_Undercapacity, the Prospective_Retailer_ Capacity and the Retailer_Remanufacturing_Capacity. The retailer evaluates his undercapacity position every six months and decides whether additional capacity is required. Retailer undercapacity is calculated by: $\mathrm{RU}(\mathrm{t})=\mathrm{RIC}(\mathrm{t})-\mathrm{PRC}(\mathrm{t})+\mathrm{RRC}(\mathrm{t})$

and the Average Retailer Undercapacity is: $A R U=\int_{t-1}^{t}[R U(t)] d t$

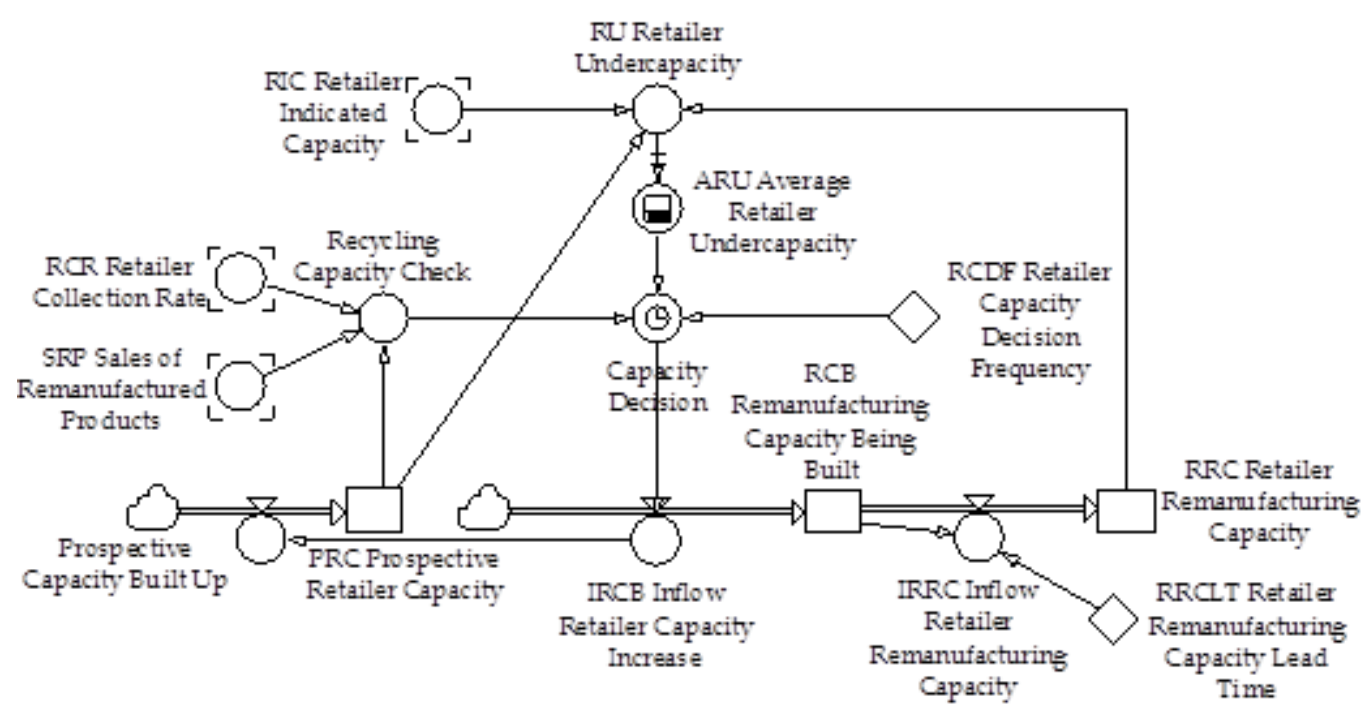

Figure 5 Stock and flow structure for the retailer remanufacturing capacity.

Prospective_Retailer_Capacity is the capacity planned by the retailer on the basis of the collected products. It becomes operational after a certain period of time. The Retailer_Indicated_Capacity is based on the orders placed for brand products that sustain the flow of used products. The retailer's Remanufacturing_Capacity_Being_Built is calculated by: 


$$
\operatorname{RCB}(\mathrm{t})=\int_{0}^{t}[\operatorname{IRCB}(\mathrm{t})-\operatorname{IRRC}(\mathrm{t})] \mathrm{dt}
$$

Remanufacturing capacity becomes operational with a lead time (RRCLT). Hence, the stock of capacity that is available for remanufacturing is: $\mathrm{RRC}(\mathrm{t})=\int_{0}^{t}[\operatorname{IRRC}(\mathrm{t})] \mathrm{dt} / \mathrm{RRCLT}$

The OEM adds capacity in a similar way taking into account the rate of used products forwarded by the retailer (Retailer_Returns), its current recycling capacity (OEM_Recycling_ Capacity), and the potential contribution that the recycled products can have on the production of brand products (Retailer_Returns_OEM_Manufacturing_Ratio). This is the ratio of the rate of returned quantities of products to the OEM, over the rate of products being manufactured. In the model, every recycled item used in manufacturing reduces the amount of required materials and the corresponding production activity by $30 \%$ while the environmental burden of the remanufacturing activity per item is $30 \%$ of the equivalent for producing a brand new product. These values are valid for automotive engines (Smith and Keoleian, 2004) and industrial tanks (Papachristos and Adamides, 2013). The product use period has been set to three years and the initial values for the costs of brand and remanufactured products were set to a ratio of 1.3 to 0.8 based on the case study in Papachristos and Adamides (2013). Initially, the secondary market was set to be $10 \%$ of the primary one.

To calculate the environmental effect of transportation logistics (pollution and consumption of natural resources), in the model, initial values where used from Papachristos and Adamides (2013) and explored further through sensitivity analysis. The distances between the market and the retailer, and the market and the OEM, were set to $60 \mathrm{Km}$ and $300 \mathrm{Km}$, respectively. Component suppliers were assumed to be situated at a distance of $60 \mathrm{Km}$ for both co-opetitors. It was further assumed that the average product unit volume was $1000 \mathrm{lt}$, while the average volume of parts required for remanufacturing was $30 \mathrm{lt}$. These values were varied also in the sensitivity analysis. The logistics environmental impact was calculated on a volume $\mathrm{x}$ distance basis for the OEM and the retailer, assumed to be proportional to fuel use, a frequently applied environmental metric (Cuthbertson and Piotrowicz, 2008).

\section{The effect of OEM operations strategies}

In order to answer the research questions stated at the end of Section 3, a number of simulations were conducted. The simulation period was 6 years with a time step of 0.5 weeks. The model decision variables for implementing OEM's response strategies identified in section 
3 , the relative market size and growth rate along with the value range that were tested for, are listed in Table 1:

Table 1 OEM strategic decision variables.

\begin{tabular}{|c|c|c|}
\hline Variable Name & Value Range & Step \\
\hline Initial_OEM_Recycling_Capacity & $1-120$ (units/year) & 20 \\
\hline Rationing_Level & $0-60 \%$ & $10 \%$ \\
\hline OEM_Learning_Exponent & $0.005-0.035$ & 0.005 \\
\hline Initial_Brand_Segment_Size & $300-900$ (units/year) & 100 \\
\hline Market_Growth_Rate & $0-7 \%$ (annual) & $1 \%$ \\
\hline
\end{tabular}

\subsection{The effect of order rationing}

Intentional partial fulfilment of retailer orders (rationing) results in less brand products sales and increased OEM competitiveness because retailer returns to the OEM are a higher proportion of OEM manufacturing which is reduced because of rationing. This leads to the development of higher OEM recycling capacity and use of recycled products in production, lower prices and hence higher OEM competitiveness. The OEM turns out to be more competitive in stable markets where these effects are more pronounced than in growing ones (Figure 6, left). Growing markets provide increasing streams of used products and a better business opportunity for the retailer/remanufacturer. Rationing has an impact on the retailer's capacity utilisation only in small OEM markets (stable and growing): its utilization increases because the retailer built less capacity. The difference in OEM and retailer competitiveness between large and small initial OEM markets results from the difference in brand products manufacturing which leads to less production related learning and higher prices, hence lower competitiveness. 

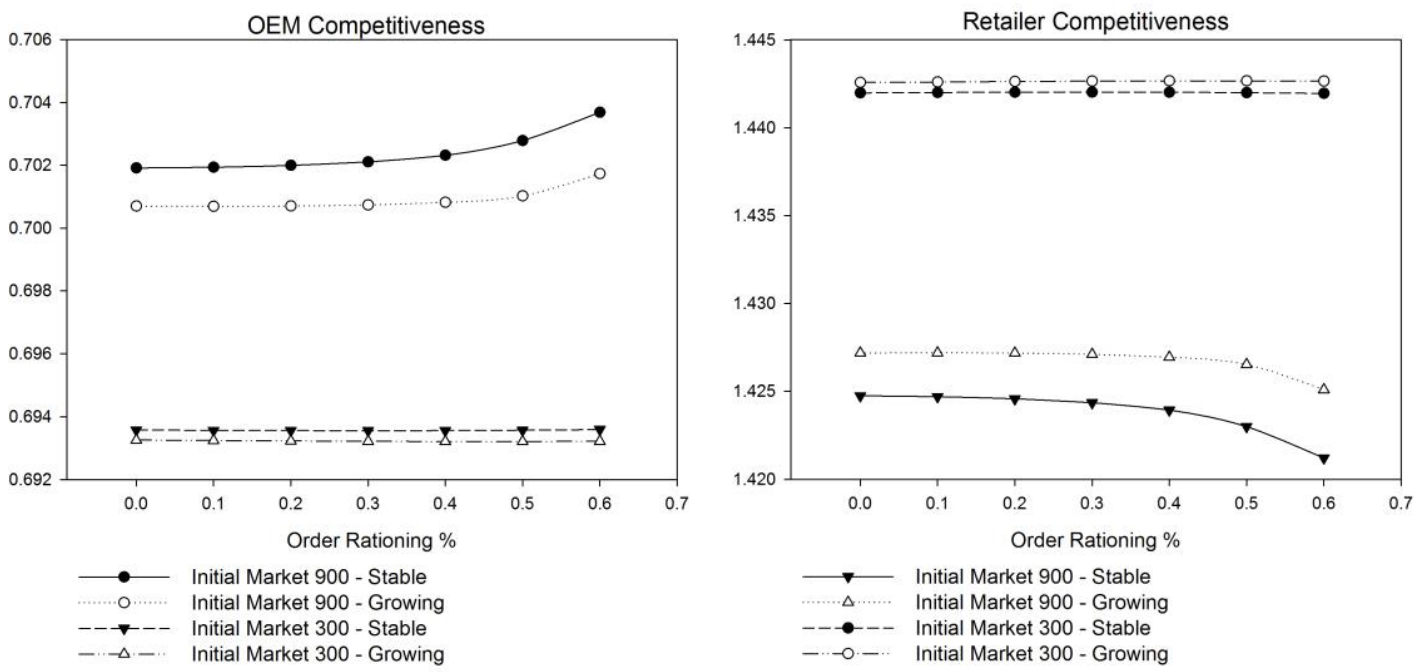

Figure 6 The effect of order rationing on average OEM and retailer competitiveness in small and large initial OEM markets, in stable and growing conditions.

The rationing strategy results in a marginal improvement of the environmental performance of the entire supply chain as it gives rise to less production activity (Figure 7 left). However, it also results in increased logistics impact (Figure 7 right) because increased flows of products find their way back to the OEM. This is more pronounced in large initial OEM market settings.
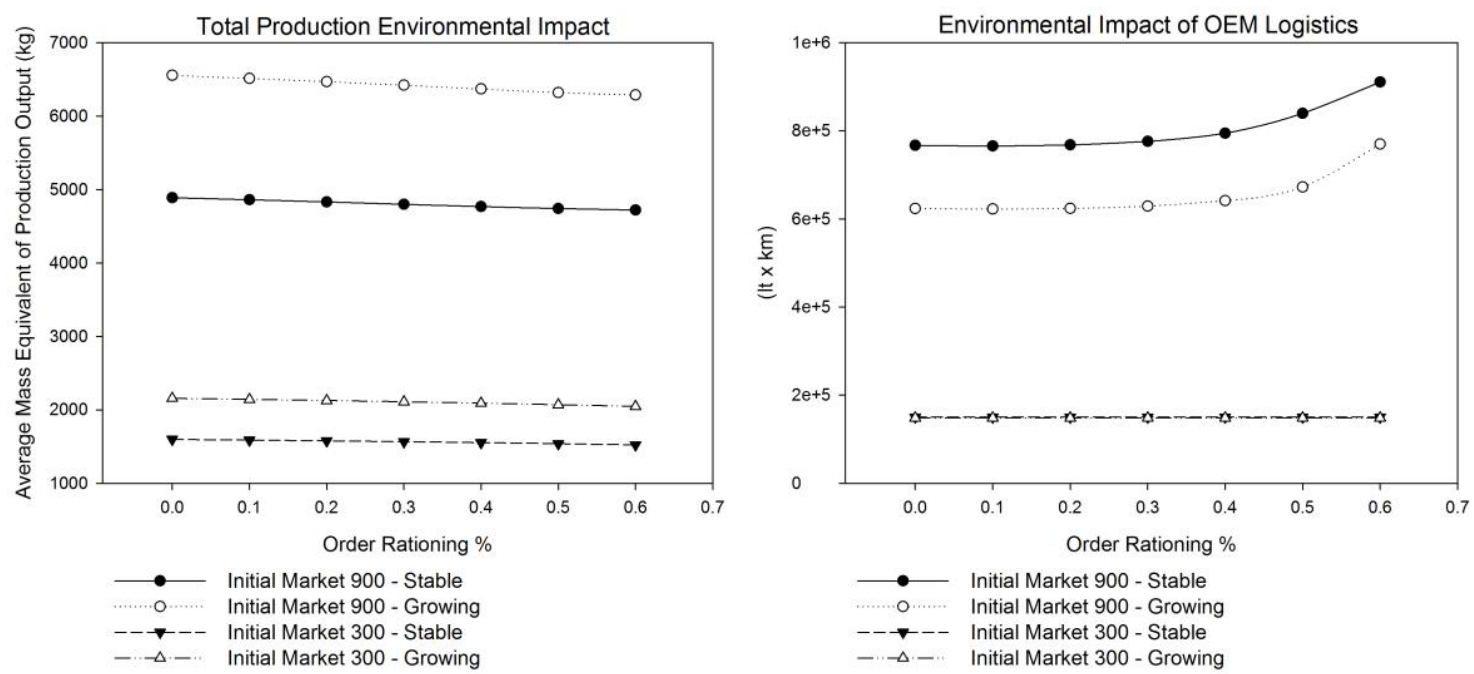

Figure 7 The effect of rationing on the environmental indicators of the supply chain, for small and large initial OEM markets, in stable and growing conditions.

\subsection{The effect of recycling}

Increasing the OEM's pre-emptive, initial recycling capacity, increases its average competitiveness in large brand markets and decreases the competitiveness of the retailer. This is because greater quantities of used products reach the OEM, are recycled, reduce the cost of brand new products and increase their attractiveness. Subsequently, this leads to more used 
products in the market, some of which are returned through the retailer to the OEM creating a reinforcing effect. Overall, the results indicate that in small markets, the retailer's competitiveness is not affected by the OEM's initial capacity since recycled quantities are smaller than in large markets. The remanufacturing capacity utilization remains relatively high as the retailer adjusts its capacity according to the size of the brand products market.
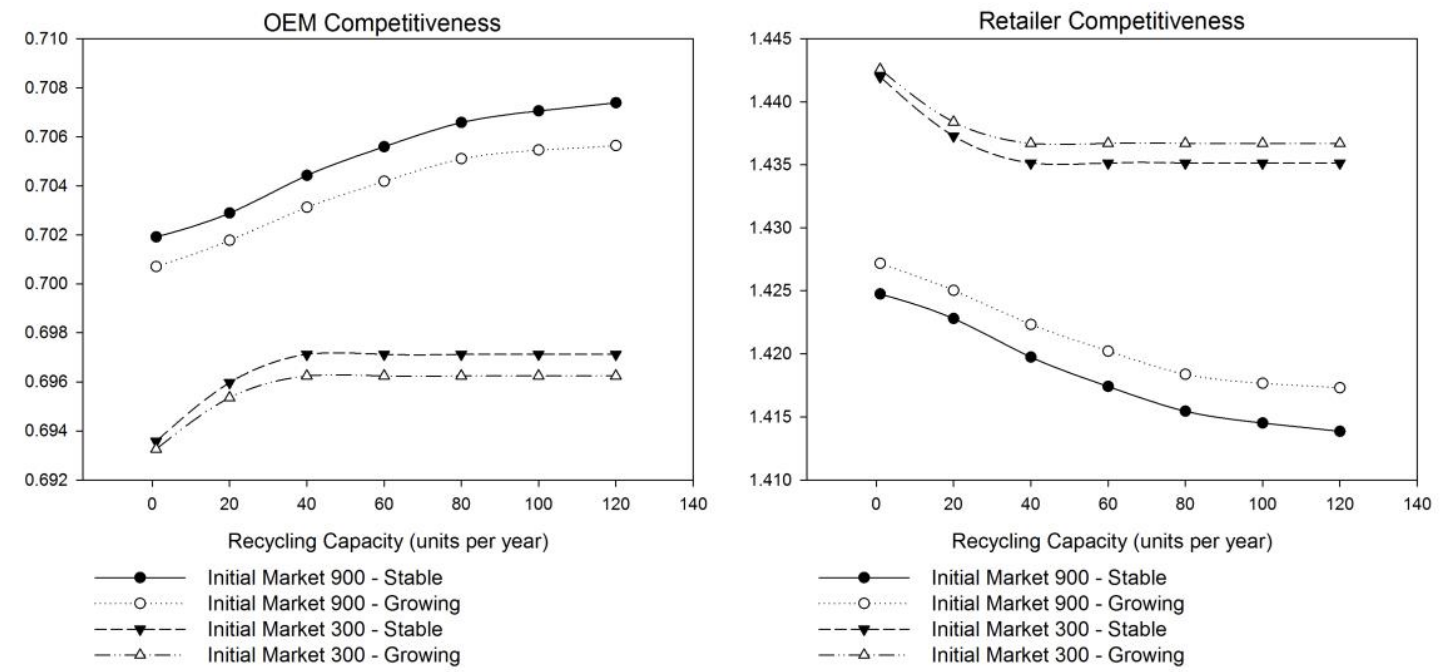

Figure 8 The effect of initial recycling capacity on average OEM and retailer competitiveness, for small and large initial OEM markets, in stable and growing conditions.

This strategy makes the OEM more competitive in large markets and as a result weakens the retailer's remanufacturing loop. Hence, more used products are shipped to the OEM for recycling, thus increasing the impact of OEM transport logistics (Figure 9).
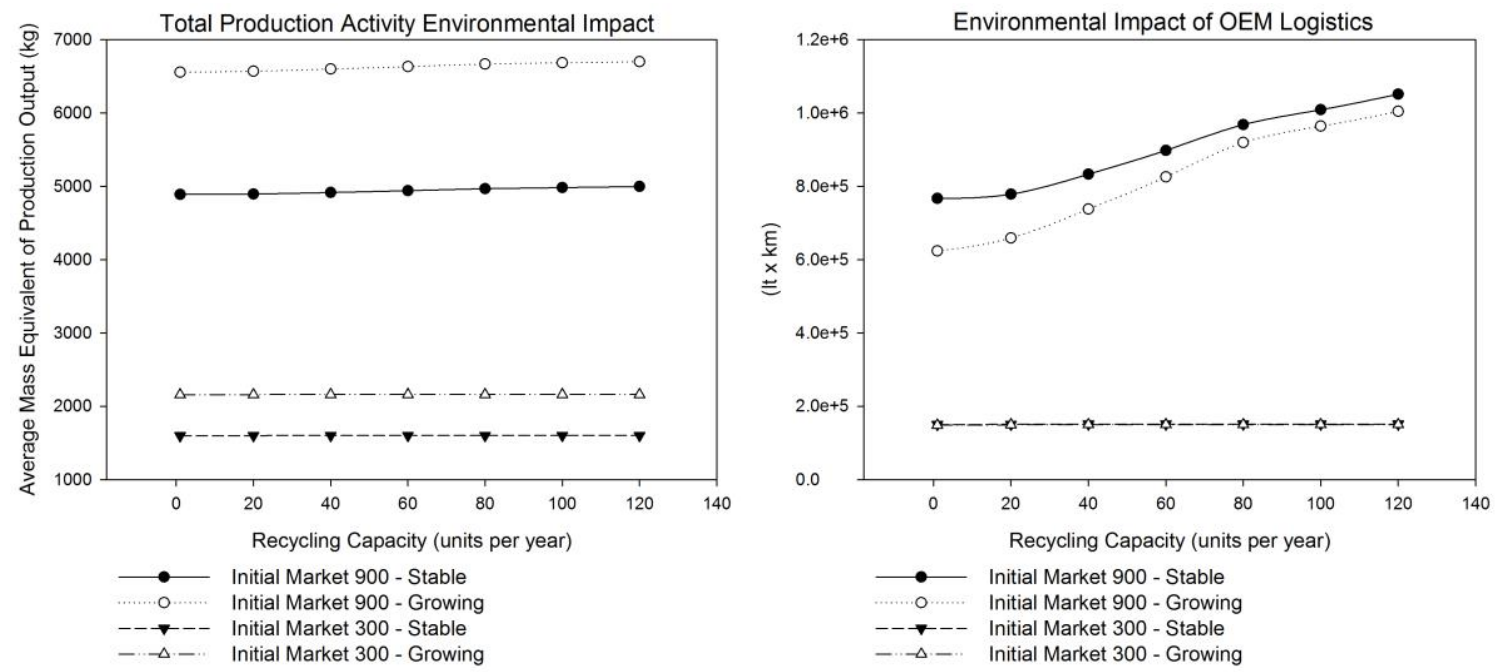

Figure 9 The effect of initial recycling capacity on the environmental indicators of the supply chain, for small and large initial OEM markets, in stable and growing conditions. 


\subsection{The effect of OEM's pace of learning in production}

Increasing the exponent of the production learning function improves OEM competitiveness. Nevertheless, the OEM can, at best, only approach the retailer's competitiveness, because the gap in the initial competiveness due to the price differential cannot be closed. The increased OEM competiveness results in slightly lower retailer remanufacturing capacity and total number of remanufactured products for all brand market sizes and growth rates. This also leads to increased quantities of products being disposed thereby increasing the environmental impact of the supply chain while lowering the logistics impact of the retailer.

\subsection{Sensitivity analysis}

Sensitivity analysis was conducted to assess the dependence of OEM strategies on the model's associated parameter values listed in Table 2. The effect of varying each one was assessed by simulating the model.

Table 2 Sensitivity analysis variables and ranges.

\begin{tabular}{lcccc}
\hline \multicolumn{1}{c}{ List of parameters } & Min & Max & Step & Units \\
\hline Impact of remanufacturing products compared to producing new & 0.3 & 0.6 & 0.1 & - \\
\hline Impact of recycled products compared to producing new & 0.6 & 0.9 & 0.1 & - \\
\hline Influence of recycling in price setting & 0.1 & 0.3 & 0.1 & - \\
\hline Remanufacturing capacity lead time & 1 & 2 & & years \\
\hline Initial remanufacturing product unit cost & 0.1 & 0.9 & 0.2 & $\begin{array}{c}\text { Monetary } \\
\text { units }\end{array}$ \\
\hline Market fractional growth & 0 & 0.07 & 0.07 & $\%$ \\
\hline Initial brand demand & 300 & 900 & 300 & $\begin{array}{c}\text { annual } \\
\text { demand }\end{array}$ \\
\hline Distance supplier - OEM & 60 & 240 & 60 & $\mathrm{~km}$ \\
\hline Distance OEM - retailer & 300 & 900 & 300 & $\mathrm{~km}$ \\
\hline Volume of product & 1000 & 3000 & 1000 & $\mathrm{lt}$ \\
\hline Volume of spares parts per product & 30 & 120 & 30 & $\mathrm{lt}$ \\
\hline Distance User - Retailer & 60 & 240 & 60 & $\mathrm{~km}$ \\
\hline
\end{tabular}

The results of the sensitivity analysis and the $\%$ of the scenarios explored for each strategy that increase the magnitude of variables relative to the reference scenario are presented in Table 3. With the rationing strategy, OEM improves its competitiveness in $43.75 \%$ of scenarios while in the remaining $56.25 \%$ the retailer is better off. The environmental impact of OEM logistics increases in $71.87 \%$ of the scenarios and there is a significant overlap $(71.42 \%)$ with scenarios where OEM competitiveness improves. In the remaining rationing strategy scenarios, the OEM improves the environmental impact of logistics as less collected used products are shipped back to him or marginally improves his competitiveness. With recycling capacity there is 
complete overlap of strategies i.e. all of those that increase OEM competitiveness, increase also the total production environmental impact and total disposed material, and the environmental impact of OEM logistics. Finally, with the learning strategy, the OEM improves competitiveness but also increases the total production environmental impact, total material use and total disposed material in all of the scenarios explored. In general competitiveness cannot be improved without increasing environmental impact.

There are also scenarios where the OEM can improve competitiveness without a corresponding increase in environmental impact. These are scenarios with no market growth and small initial brand markets. But, stable and small brand markets are perhaps not going to be enough of a motive for the OEM to commit resources in order to respond strategically to the retailer. The actual value of improvement in OEM competitiveness is less than $1 \%$ compared to the reference scenario, a value which is not significant relative to competitiveness improvements achieved with the learning and recycling capacity strategies.

Overall, out of the three strategies, the OEM might prefer the learning strategy compared to recycling capacity or rationing, if its priority is competitiveness, because it achieves greater relative gains in competitiveness than the increase in environmental impact. Recycling and rationing strategies have a symmetrically opposite effect.

Table 3 Aggregate results of sensitivity analysis.

\begin{tabular}{|l|c|c|c|}
\multicolumn{1}{c}{ Output Variable } & Learning & \multicolumn{1}{c|}{$\begin{array}{c}\text { Recycling } \\
\text { Capacity }\end{array}$} & $\begin{array}{c}\text { Order } \\
\text { Rationing }\end{array}$ \\
\hline OEM competitiveness & 100 & 100 & 43.75 \\
\hline Retailer competitiveness & 0 & 0 & 56.25 \\
\hline Total Production Environmental Impact & 100 & 100 & 0 \\
\hline Total Materials Use & 100 & 34.37 & 0 \\
\hline Disposed Material & 100 & 100 & 0 \\
\hline Environmental Impact of OEM logistics & 31.25 & 100 & 71.87 \\
\hline Environmental Impact of Retailer logistics & 18.75 & 31.25 & 3.125 \\
\hline
\end{tabular}

In conclusion, regarding question 1 about the available OEM strategic responses and their effectiveness, accelerating the pace of production related learning is the most effective strategy. The key insight is though that there are inherent trade-offs imposed by the assumed sociotechnical regime on the configuration of the interactions in the supply chain, when trying to integrate competitive and environmental aspects in the OEM operations strategy. OEM responses are moderately successful but they are not sufficient for addressing simultaneously the competitive and environmental performance objectives. Hence, with regard to question 2 
on addressing both competitive and environmental performance objectives, it is concluded that this is rather difficult. Consequently, as will be argued in section 7 , the likelihood that the OEM will escape the competitive lock-in situation in order to attain both objectives is rather small.

\section{Causes of inertia}

In the competitive situation analysed in the previous sections, the OEM faces a trade-off between improving its position vis-a-vis the retailer and the environmental performance of the supply chain. The OEM has been assumed to respond by committing to operations strategies that shift demand and production towards brand new products. This excludes the prospect of exploring ways for significantly reducing the environmental impact of production activities through remanufacturing or recycling.

OEM managers are in a position where decisions have to be taken about committing firm resources for strategic exploitation or exploration, a classic dilemma (March, 1991). The assumed sociotechnical regime in which actors operate, constitutes a particular competitive business environment where various corporate and operation strategies can be explored for achieving business and environmental objectives. Obviously, it is possible to argue that the predicament of the OEM can be overcome by strategically reorienting and collaborating in the reverse supply channel to move towards environmental sustainability as mentioned in section 2 (Vachon and Klassen, 2008; Green et al., 2012; Vachon and Klassen, 2007). However, it requires cooperation across the supply chain and involves resolving issues relating to performance measurement, information systems, responsibility sharing, and standardization across the supply chain, in effect increasing the managerial challenges (Vachon and Klassen, 2006). Performance measurement is challenging because it is difficult to trace it to one particular entity within the chain or link environmental to financial performance (Hervani et al., 2005; Angel del Brio and Junquera, 2003). Other complexities involved in green supply chain practices such as customer and cost pressures and regulation uncertainty only add up to the obstacles (Hsu and $\mathrm{Hu}, 2008$ ).

While the system dynamics model of this paper was not built to explore ways that supply chain actors self organize and overcome these barriers through strategic business decision making, this issue has been explored in the literature (Levinthal, 1997). Drawing on insights from this literature, managers are most likely to take decisions that will lock-in the OEM further into 
competition with the retailer that renders unattainable the achievement of both competitive and environmental objectives.

Two arguments will be made to support this, drawing broadly on: (i) the allocation of resources and the management of exploration and exploitation activities in a firm, and (ii) the effect that the complexity of the business environment has on organizational decision making, firm performance and the attainment of firm goals. These are directly related to: (i) managerial barriers to firm strategy exploration i.e. the suppression of risky exploration activities in the face of adverse financial outcomes (competition from remanufacturing) that can potentially lead the firm to escalate its commitment into current ongoing exploitation activities, and (ii) complexity barriers i.e. the increased risk and complexity that firms face when taking business and environmental performance goals into consideration.

\section{Managerial barriers to firm exploration}

Firms strive to achieve and maintain a desired balance in the use of organizational resources allocated to exploration (innovation) and exploitation activities (generating returns on investment) (Lavie et al., 2010; Gupta et al., 2006; March, 1991). However, in the long run, particularly when experiencing prolonged success, firms tend to give resource and competence exploitation activities precedence over exploration activities (Helfat et al., 2007). According to a recent McKinsey report they are (Bradley et al., 2013, p8): "more geared to confirming existing hypotheses than to testing new ones". In effect they find themselves caught in a "success trap" of their own doing, which stops them from investing and engaging in exploration activities in order to adapt to their environment (Leonard-Barton, 1992; Levinthal and March, 1993; Tripsas and Gavetti, 2000; Helfat et al., 2007). Failure to perceive and respond appropriately to disruptive events by taking the necessary decisions and adjusting firm strategy, stems from the cognitive processes of managers that constrain their ability to effect strategic change when it is most required and can eventually lead to organizational decline (Mellahi and Wilkinson, 2004; Sheppard and Chowdhury, 2005; Christensen, 2011).

Walrave et al. (2011) drawing on earlier theoretical work on self justification theory (Staw, 1981; Brockner, 1992), explore how the "success trap" works. They develop a process theory that explains how the interaction of managers, stakeholders and firm exploitation and exploration activities, can keep or delay the firm from engaging in substantial exploration activities. If the organization has a culture in which: (i) people are unwilling to admit failure 
and thus persist with a course of action driven by sunk costs or (ii) value consistency in behaviour, then it will promote strategies that focus on exploitation of current competences and escalate commitment to strategies even if they lead to failure (Kahneman, 2011).

This is precisely the nature of the strategies explored in the present paper where the OEM seeks to increase its competitiveness against the retailer. They create a path dependent situation where persistence in exploitation leads to business success in the short term and increased environmental impact, but also to less exploration. This is counter productive to a sociotechnical trajectory of sustainable operations and thus amounts to inertia. What is required in order to move towards this direction is exploration. However, because of the 'success trap' this is unlikely.

\section{Complexity barriers to firm exploration}

Even when managers overcome the "success trap" and are willing to explore other strategic options, there are certain challenges in doing so. Through their decisions, they should: (i) not lock the firm early into the first set of good strategic choices that they come across, (ii) stop their search efforts and stabilize their decisions once a really good set of choices is found, and (iii) not attempt to uncritically imitate the strategies of other competitors.

Several implications from these conditions, can be worked out from viewing manufacturing firms and supply networks as complex adaptive systems (McCarthy, 2004; McCarthy and Tan, 2000; Choi et al., 2001). The difficulties in exploring strategic choices lie in the interdependency of decisions that have been shown to affect the adaptation of the firm and the level of fitness to its business environment, a process which is conceptualised as an exploration of a 'rugged' landscape (Levinthal, 1997). This process has been explored in a stream of literature that utilised and extended the NK model in numerous ways in order to explore a variety of organisational decision issues (McKelvey, 1999; Rivkin, 2000; Rivkin and Siggelkow, 2003; 2007; Ethiraj and Levinthal, 2004; 2009; Lenox et al., 2006). Briefly the NK model considers an entity of $\mathrm{N}$ decision attributes (the firm in this case), or performance objectives (business and environmental), with $\mathrm{K}$ connections between them. Thus, if $\mathrm{K}=0$ all attributes are completely disconnected and can be influenced independently of one another and it is easier to arrive at an optimum decision. 
Under a complex adaptive systems perspective the search for OEM responses, constitutes a local adaptation on the competitive business landscape. Incorporating environmental impact considerations effectively increases the interdependency of strategic decisions $(\mathrm{K})$ and the number of goals $(\mathrm{N})$ the OEM pursues, because of all the barriers discussed previously. Furthermore, engaging in recycling operations, requires constant monitoring of product life cycles which is also disrupted by the competitive behaviour of the remanufacturer (Atasu et al., 2008). Thus the OEM faces a more complex, "rugged" fitness landscape. It has been shown that in such situations of increased complexity, a local adaptation behaviour is not an effective response and it is linked to organizational decline because it is likely to lead to a "valley" rather than a higher performance "peak" (Levinthal, 1997).

It has also been shown that when organizations pursue multiple correlated performance goals, as is the case with decisions relating to forward and reverse supply channels (Kocabasoglu et al., 2007), they face increased organizational interdependencies and they may get into a lock-in situation of responding to business competition (Ethiraj and Levinthal, 2009). The implication is that managers are not able to identify strategies that perform well across the range of organizational goals.

A plausible alternative way forward is for the OEM to identify and imitate successful strategies of other OEMs that face similar competitive challenges. However, the complexity of a strategy stemming from the interdependencies among decision factors, coupled with limits on what managers know about their rival's strategies and can implement, raise a barrier to imitation (Rivkin, 2000). Furthermore, being in a competitive environment OEMs have an incentive to raise barriers to strategy imitation from their rivals in order to maintain their competitive advantage. Consequently, the barriers to successful strategy imitation point towards crafting a novel supply chain strategy that incorporates environmental considerations (Hart, 1995; Carter and Rogers, 2008).

This creates an interesting paradox where integrating environmental parameters and thus further complicating firm strategy, actually makes it harder for these strategies to be copied and diffuse through imitation. What this implies from a sociotechnical perspective is that a niche where competitive and environmental aspects are successfully integrated in supply chains will likely remain a niche for a considerable time rather than have an immediate effect in the regime. 
Drawing on the discussion based on the NK model, it is necessary to reduce the complexity of the environment and thus the decision making complexity for OEM strategies. It would require institutional changes as well so that the interconnectedness of business and environmental goals became more straightforward and thus reduce the complexity that firms face. Reducing the complexity of the environment will result in a reduction of $\mathrm{N}$ and possibly $\mathrm{K}$ thus making navigating successfully the competitive business landscape less difficult. This could channel the firm's exploration activities towards a more sustainable pathway and facilitate the development and implementation of environmentally benign supply chain practices (Vachon and Klassen, 2006). It would simultaneously be conducive to the rapid adoption of novel strategies thus overcoming the obstacles of strategy imitation and niche growth.

\section{Conclusions}

This paper aimed at contextualising supply chain research and highlighting its relevance for overcoming inertia in shifting a sociotechnical system to a sustainability trajectory. This was accomplished by presenting a capital goods supply chain model where retailers initiate remanufacturing operations and compete against OEM brand products. The example and the subsequent discussion from a sociotechnical perspective illustrate how interactions between supply chain actors may amount to transition inertia.

Simulation results of the model illustrate that achieving business and environmental goals is difficult. In most of the OEM strategic response scenarios considered, the OEM could not improve both. This holds within the range of sensitivity analysis conducted with the model for capital goods supply chains. It appears that remanufacturing by the retailer close to the market is required to minimise the impact of logistics and improve the environmental performance of the supply chain. The retailer also needs the presence of competitive OEM brand products in the market to provide a steady stream of used products for remanufacturing. Hence, if both business and environmental goals are to be addressed, the OEM has to overcome the trade-off between competitiveness and environmental performance.

This requires a fundamental OEM strategy reorientation and exploration of new strategies. Such a reorientation is unlikely to take place or be successful due to the barriers discussed in section 7. Thus a first level of inertia is at the supply chain or niche level. However, even in the event that such strategies are implemented at the niche level, barriers to their diffusion in the 
sociotechnical system through imitation, when firms seek and guard their competitive advantage, constitute a second level of system inertia.

The discussion on the barriers associated with OEM strategic reorientation has an interesting paradoxical implication: namely, strategies directed at sustainability do not emerge easily in a competitive institutional environment and when they do it is unlikely that they will diffuse through imitation because of competition. Thus bottom-up large scale sociotechnical change is hampered by inertia. The way out of this is to reduce the complexity firms face in their sociotechnical environment so that strategy exploration is encouraged.

This would allow OEMs to reconsider the relations and terms of competition with their retailers: they might cooperate with them in remanufacturing, or organise an efficient decentralised recycling network that keeps recycling and use of acquired materials as close as possible to the point of collection. Finally, a more radical move is a change of the OEM's business model towards service provision where products/equipments are leased to the customers while a set of services, such as maintenance and upgrading is offered by the retailers/resellers. This inevitably requires a more pervasive change that includes the use/customer elements of the sociotechnical system.

\section{Acknowledgements}

This work has been funded by NWO grant M74021. The author would like to thank two anonymous reviewers and the editor for comments that significantly improved the paper.

\section{References}

Angel del Brio, J., Junquera, B., 2003. A review of the literature on environmental innovation management in SMEs: implications for public policies. Technovation 23 (12), 939-48.

Atasu, A., Guide, V.D., Van Wassenhove, L.N., 2008. Product reuse economics in closed-loop supply chain research. Production and Operations Management 17(5), 483-496.

Atasu, A., Guide, V.D., Van Wassenhove, L.N., 2009. So what if remanufacturing cannibalizes new product sales?. California Management Review 52(2), 56-76.

Barney, J., 1986, Strategic factor markets: expectations, luck, and business strategy. Management Science 32, 1231- 1241.

Barney, J., Wright, M., Ketchen, D., J., 2001. The Resource Based View of the firm ten years after 1991. Journal of Management, 27, $625-641$ 
Bjorklund, M., Martinsen, U., Abrahamsson, M., 2012. Performance measurements in the greening of supply chains. International Journal of Supply Chain Management 17(1), 29 - 39

Bradley, C., Dawson, A., Montard, A., 2013. Mastering the building blocks of strategy. McKinsey report

Brockner, J., 1992. The escalation of commitment to a failing course of action: Toward theoretical progress. Academy of Management Review, 17(1), 39 - 61

Burgos Jiménez, J. de, Céspedes Lorente, J.J., 2001. Environmental performance as an operations objective. International Journal of Operations and Production Management 21(12), 1553-1572.

Carter, C.R., Rogers, D.S., 2008. A framework of sustainable supply chain management: moving toward new theory. International Journal of Physical Distribution \& Logistics Management, 38(5), $360-387$

Choi, T.Y., Dooley, K.J., Rungtusanatham, M., 2001. Supply networks and complex adaptive systems: Control versus emergence. Journal of Operations Management, 19, 351 - 366

Christensen, C., 2011. The Innovator's Dilemma: The Revolutionary Book That Will Change the Way You Do Business. HarperBusiness, US

Cuthbertson, R., Piotrowicz, W., 2008. Supply chain best practices - identification and categorisation of measures and benefits. International Journal of Productivity \& Performance Management 57(5), 389 - 404.

Debo, L.G., Toktay, L.B., Van Wassenhove, L.N., 2006. Joint life-cycle dynamics of new and remanufactured products, Production and Operations Management 15(4), 498-513.

Dierickx, I., Cool, K., 1989. Asset stock accumulation and sustainability of competitive advantage, Management Science 35, 1504-1511.

Ellen MacArthur Foundation, 2012. Towards the Circular Economy: Economic and business rationale for an accelerated transition.

Ethiraj, S. K., Levinthal, D.A., 2004. Bounded rationality and the search for organizational architecture: An evolutionary perspective on the design of organizations and their evolvability. Administrative Science Quarterly, 49(3), 404 - 437

Ethiraj, S., Levinthal, D.A., 2009. Hoping for A to Z while rewarding only A: Complex organizations and multiple goals. Organization Science, 20(1), 4-21

Ferguson, M.E., Toktay, L.B., 2006. The effect of competition on recovery strategies. Production and Operations Management 15(3), 351-368.

Fleischmann, M., Dekker, R., Van der Laan, E., Van Numen, J., Van Wassenhove, L., Ruwaard, J.. 1997. Quantitative models for reverse logistics: a review. European Journal of Operational Research 103, 1-17. 
Geels, F.W., Schot, J., 2007. Typology of sociotechnical transitions pathways, Research Policy, 36, $399-417$.

Geels, F.W., 2011. The multi-level perspective on sustainability transitions: responses to seven criticisms. Environmental Innovation and Societal Transitions 1, 24-40

Green, K.W.Jr., Zelbst, P.J., Meacham, J., Bhadauria, V.S., 2012. Green supply chain management practices: impact on performance. International Journal of Supply Chain Management 17(3), $290-305$

Grin, J., Rotmans, J., Schot, J.W., 2010. Transitions to sustainable development. Routledge Studies in Sustainability Transitions. Routledge, New York

Großler, A., 2007. A dynamic view of strategic resources and capabilities applied to an example from the manufacturing strategy literature. Journal of Manufacturing Technology Management, 18(3), 250-256.

Guide, V.D.R.Jr., Van Wassenhove, L.N., 2009. The evolution of closed loop supply chain research. Operations Research 51(1), $10-18$

Gupta, A.K., Smith, K.G., Shalley, C.E., 2006. The interplay between exploration and exploitation. Academy of Management Journal, 49(4), 693 - 706

Hart, S.L., 1995. A natural-resource-based view of the firm. Academy of Management Review 20(4), 986-1014.

Hazen, B.T., Overstreet, R.E., Jones-Farmer, A., Field, H.S., 2012. The role of ambiguity tolerance in consumer perception of remanufactured products. International Journal of Production Economics 135, 781-790.

Heese, H.S., Cattani, K., Ferrer, G., Gilland, W., Roth, A.V. 2005. Competitive advantage through take-back used products. European Journal of Operational Research 164, 143-157.

Helfat, C.E., Finkelstein, S., Mitchell, W., Peteraf, M., Singh, H., Teece, D., Winter, S. G., 2007. Dynamic capabilities: Understanding strategic change in organizations. Blackwell, Oxford

Hervani, A.A., Helms, M.M., Sarkis, J., 2005. Performance measurement for green supply chain management. Benchmarking: An International Journal 12(4), 330 - 53.

Hill, T., 2000. Manufacturing Strategy: Text and Cases. Palgrave, New York, NY.

Hsu, Hu., 2008. Green supply chain management in the electronic industry. International Journal of Environmental Science and Technology 5(2), 205 - 216

Jermier, J.M., Forbes, L.C., 2003. Greening organizations: critical issues, In: Alvesson, M., Willmott, H. (Eds.), Studying Management Critically. Sage Publications, London, 157-176.

Jones, C.A., Levy, D.L., 2007. North American business strategies towards climate change. European Management Journal 25(6), 428-440. 
Kastalli, I.V., Van Looy, B., 2013. Servitization: Disentangling the impact of service business model innovation on manufacturing firm performance. Journal of Operations Management 31, $169-180$

Kahneman, D., 2011. Thinking fast and slow. Penguin, US

Kleber, R., Zanoni, S., Zavanella, L., (2011). On how buyback and remanufacturing strategies affect the profitability of spare parts supply chains. International Journal of Production Economics 133, 135-142.

Kleindorfer, P.R., Singhal, K., Van Wassenhove, L.N., 2005. Sustainable operations management, Production and Operations Management 14(4), 482-492.

Kocabasoglu, C., Prahinski, C., Klassen, R., 2007. Linking forward and reverse supply chain investments: The role of business uncertainty. Journal of Operations Management, 25(6), 1141 $-1160$

Kunc, M.H., Morecroft, J.D.W. 2009. Resource-based strategies and problem structuring: using resource maps to manage resource systems, Journal of the Operations Research Society, 60, 191-199.

Lavie, D., Stettner, U., Tushman, M.L., 2010. Exploration and exploitation within and across organizations. Academy of Management Annals, 4, 109 - 55

Lenox, M.J., Rockart, S.F., Lewin, A.Y., 2006. Interdependency, competition, and the distribution of firm and industry profits, Management Science, 52 (5), 757 - 773

Levinthal, D.A., March, J.G., 1993. The myopia of learning. Strategic Management Journal, $14,95-112$

Levinthal, D.A., 1997. Adaptation on rugged landscapes. Management Science, 43(7), 934 950

Leonard-Barton, D., 1992. Core capabilities and core rigidities: A paradox in managing new product development. Strategic Management Journal, 13(5), 111 - 125

March, J.G., 1991. Exploration and exploitation in organizational learning. Organization Science, 2(1), $71-87$

Matsumoto, M., 2009. Business frameworks for sustainable society: a case study on reuse industries in Japan. Journal of Cleaner Production 17, 1547 - 1555.

Matsumoto, M., Umeda, Y., 2011. An analysis of remanufacturing practices in Japan. Journal of Remanufacturing 1(2), $1-11$

McCarthy, I.P., Tan, Y.K., 2000. Manufacturing competitiveness and fitness landscape theory. Journal of Materials Processing Technology, 107, 347 - 352

McCarthy, I.P., 2004. Manufacturing strategy: Understanding the fitness landscape. International Journal of Operations \& Production Management, 24(2), 124-150 
McKelvey, B., 1999. Avoiding complexity catastrophe in coevolutionary pockets: Strategies for rugged landscapes. Organizational Science, 10, $294-321$

Mellahi, K., Wilkinson, A., 2004. Organizational failure: a critique of recent research and a proposed integrative framework. International Journal of Management Reviews, 5-6(1), 21 41

Mitra, S., Webster, S., 2008. Competition in remanufacturing and the effects of government subsidies. International Journal of Production Economics 111, 287-298.

Mollona, E., 2002. A competence view of firms and resource accumulation systems: A synthesis of resource-based and evolutionary models of strategy-making. In: Morecroft J., Sanchez, R., Heene, A. (Eds.), Systems Perspectives on Resources, Capabilities, and Management Processes, Elsevier Science, Oxford, 93-125.

Morecroft, J., 2002. Resource management under dynamic complexity. In: Morecroft J., Sanchez, R., Heene, A. (Eds.), Systems Perspectives on Resources, Capabilities, and Management Processes, Elsevier Science, Oxford, 19-39.

Morecroft, J., 2007. Strategic Modelling and Business Dynamics: A Feedback Systems Approach. John Wiley \& Sons, Chichester.

Newman, W.R., Hanna, M.D., 1996. An empirical exploration of the relationship between manufacturing strategy and environmental management: two complementary models. International Journal of Operations and Production Management 16(4), 69-87.

Oliva, R., Kallenberg, R., 2003. Managing the transition from products to services. International Journal of Service Industry Management, 14(2), 160 - 172.

Östlin, J., Sundin, E., Björkman, M., 2008, Importance of closed-loop supply chain relationships for product remanufacturing. International Journal of Production Economics 115(2), 336-348.

Porter, M.E., Reinhardt, F.L., 2007. A strategic approach to climate. Harvard Business Review 85(10), 28-34.

Papachristos G., Adamides E., 2013. Internal supply-chain competition in remanufacturing: operations strategies, performance and environmental effects, in press in International Journal of Logistics Systems and Management

Qiang, Q., Ke. K., Anderson, T. Dong, J., 2013. The closed-loop supply chain network with copetition distribution channel investment and uncertainties. Omega 41(2), 186 - 194

Rivkin, J.W., 2000. Imitation of complex strategies. Management Science, 46(6), $824-844$

Rivkin, J.W., Siggelkow, N., 2003. Balancing search and stability interdependencies among elements of organizational design. Management Science, 49(3), 290 - 31

Rivkin, J.W., Siggelkow, N., 2007. Patterned interactions in complex systems. Management Science, 53(7), $1068-1085$ 
Rumelt, R.P., 1984. Towards a strategic theory of the firm. in (ed) Lamb, R.B., Competitive Strategic Management. pp. 556-570, Prentice-Hall, Englewood Cliffs, US

Sarkis, J., Zhu, Q., Lai, K., 2011. An organizational theoretic review of green supply chain management literature. International Journal of Production Economics 130, 1-15.

Seitz, M.A., 2007, A critical assessment of motives for product recovery: the case of engine remanufacturing. Journal of Cleaner Production 15, 1147-1157.

Sheppard, J.P., Chowdhury, S.D., 2005. Riding the wrong wave: organizational failure as a failed turnaround. Long Range Planning, 38, 239 - 60

Slack, N., Lewis, M., 2002. Operations Strategy. Prentice Hall, Harlow.

Smith, V.M., Keoleian, G.A., 2004. The value of remanufactured engines. Journal of Industrial Ecology 8(1-2), $193-221$

Staw, B.M., 1981. The escalation of commitment to a course of action. Academy of Management Review, 6(4), 577 - 587

Sterman, J.D., 2000. Business Dynamics: Systems Thinking and Modeling for a Complex World. McGraw Hill, New York.

Sundin, E., Bras, B., 2005. Making functional sales environmentally and economically beneficial through product remanufacturing. Journal of Cleaner Production 13, 913-925.

Teece, D.J., 1984. Economic analysis and strategic management. California Management Review, 26(3), 87 - 110

Teece, D.J., Pisano, G., Shuen, A., 1997. Dynamic capabilities and strategic management. Strategic Management Journal, 18, 509 - 533

Tibben-Lembke, R.S., 2002. Life after death: reverse logistics and the product life cycle. International Journal of Physical Distribution and Logistics Management 32, 223-244.

Toffel, M.W., 2004. Strategic management of product recovery. California Management Review 46(2), 120-141.

Tripsas, M., Gavetti, G., 2000. Capabilities, cognition, and inertia: evidence from digital imaging. Strategic Management Journal, 21, 1147 - 1161

Vachon, S., Klassen R.D., 2008. Environmental management and manufacturing performance: The role of collaboration in the supply chain. International Journal of Production Economics $111,299-315$

Vachon, S., Klassen, R.D., 2006. Extending green practices across the supply chain: The impact of upstream and downstream integration. International Journal of Operations and Production Management 26(7), 795 - 821

Walrave, B., van Oorschot, K.E., Romme, A.G.L., 2011. Getting trapped in the suppression of exploration a simulation model. Journal of Management Studies. 48(8), 1727 - 1751 
Wernerfelt, B., 1984. A resource-based view of the firm. Strategic Management Journal 1984. $5(2), 171-181$ 